\title{
Heterogeneity in Farmers' Social Preferences and the Design of Green Payment Schemes
}

\author{
Prasenjit Banerjee $^{1}$ (D) Rupayan Pal ${ }^{2} \cdot$ Ada Wossink $^{1} \cdot$ James Asher $^{1}$
}

Accepted: 9 December 2020 / Published online: 25 January 2021

(c) The Author(s) 2021

\begin{abstract}
We examine how social preferences affect the workings of voluntary green payment schemes and show that a regulator could use facilitation services along with a social reward to generate better ecological outcome at less cost by exploiting a farmer's social preferences to gain a green social-image/reputation. To motivate our model, we first present the results of an incentivized elicitation survey in Scotland which shows that there is a social norm of biodiversity protection on private land among farmers. Moreover, the results of a discrete choice experiment reveal that farmers are willing to give up economic rents for more publicity of their conservation activities; this confirms the relevance of reputational gain in the context of green payment schemes. Our model assumes two types of farmers, green and brown, with a green farmer taking more biodiversity protection actions than a brown farmer. We design a menu of contracts that offers both monetary incentives and non-monetary incentives (a facilitation service with social reward) to induce both type of farmers to join the scheme and to exert first-best levels (i.e., symmetric information levels) of action. Results show that under asymmetric information the regulator can implement the symmetric information equilibrium levels of biodiversity protection actions with only non-monetary incentives for the green farmer and only monetary incentives for the brown farmer. This implies that a regulator can ensure better environmental outcomes, at a lower cost, by exploiting farmers' social preferences and by offering non-monetary incentives.
\end{abstract}

Keywords Mechanism design · Social norm · Esteem · Motivation crowding $\cdot$ Signalling · Public goods $\cdot$ Agriculture

JEL Classification D03 · Q57 · Q58 · D82

Supplementary Information The online version contains supplementary material available at https:// doi.org/10.1007/s10640-020-00529-7.

Prasenjit Banerjee

prasenjit.banerjee@manchester.ac.uk

1 Economics, University of Manchester, Oxford Road, Manchester M13 9PL, UK

2 Indira Gandhi Institute of Development Research (IGIDR), Film City Road, Santosh Nagar, Goregaon (E), Mumbai 400065, India 


\section{Introduction}

A burgeoning stream of studies investigates the role of personal and social norms in farmers' environmental management behaviour (for an overview see Dessart et al. 2019). Empirical research shows that farmers engage in certain environmental activity without any payment which suggest that intrinsic and social goals play a role (see e.g., Mills et al. 2018). In parallel there is emerging evidence of "an environmentally compatible nature of good farming identity" (e.g., Riley 2016). Whereas the relevance of behavioural factors ${ }^{1}$ has been acknowledged in recent policy reports at national and international levels, their potential has so far been underused in agri-environmental policy design (Lourenço et al. 2016; OECD 2017).

Voluntary green payment policies are increasingly used as an instrument to enhance the supply of environmental public goods from land that remains in agricultural production (OECD 2015; Arguedas and van Soest 2011; Anthon et al. 2010). In the European Union, for example, it has been mandatory for EU member states to offer farmers voluntary agrienvironmental schemes since the early 1990s. It has been suggested that incentives leveraging the non-financial behavioural factors that have a bearing on farmers' uptake of more sustainable practices would enable better results in delivering environmental and public goods and more cost-effective approaches. ${ }^{2}$ Analysis of farmers' underlying motives could help to propose policy directions to move farmers from 'tick box compliance' (with regulatory requirements of voluntary agri-environmental schemes) to a committed environmental stewardship with better and more sustained ecological outcomes (Lokhorst et al. 2011).

Such an analysis is reported in what follows. We first report on empirical work that supports the assumptions underlying our proposed policy design. Results from an incentivized survey (Krupka and Weber 2013) provide confirmation of the existence of a social norm of environmental concern among farmers in Scotland. In addition, a choice experiment with the same sample shows that public recognition of their environmental activity is worth $£ 3.85$ per hectare to the farmers on average.

In our theoretical model, we start by distinguishing 'green' farmers from 'brown' farmers based on their relative intrinsic preference for money. 'Green' farmers are less concerned about monetary compensation for taking biodiversity protection action on the private farmland than are 'brown' farmers. In the presence of asymmetric information about the true types, a standard mechanism would prescribe a menu of contracts and, following the Revelation Principle, each type of farmer would self-select their appropriate contracts.

\footnotetext{
1 Dessart et al. (2019, p. 419) distinguish three types of behavioural factors that have a bearing on a farmer's decision-making in the context of the voluntary adoption of conservation activities: cognitive, social, and dispositional. They organise these factors conceptually based on their 'distance' (proximal-distal) from the decision-making in question. Cognitive factors are proximal and relate to learning and reasoning; they include farmers' perceptions of the relative benefits, costs and risks associated with a practice or whether they feel that they are skilled enough to adopt this practice. Dispositional factors are the most distal: they are relatively stable, internal variables related to a given individual, such as personality, motivations, values, beliefs, general preferences, and objectives. Social factors relate to farmers' interactions with other individuals (e.g., other farmers or advisors) and include social norms and signalling motives. Social factors may be proximal or distal; for instance, injunctive norms (i.e., what farmers perceive others expect from them) may push farmers to adopt a practice. Note that this classification excludes coordinated efforts between farmers to protect the natural environment, which are associated with distinct behavioural factors (Banerjee et al. 2017).

${ }^{2}$ Budgets are substantial. For example, the EU expenditure on agri-environment measures totalled to nearly 20 billion EUR or 22 percent of the expenditure for rural development for the 2007-2013 budgeting period (European Commission 2018). Agri-environment measures were included under the EU's Rural Development Regulation (Pillar 2) with regulation 1698/2005. Empirical studies indicate that the schemes often deliver only moderate ecological gains (Batáry et al. 2015).
} 
Such a menu of contracts is useful to resolve adverse selection problems: a regulator should not pay a green farmer to avoid motive crowding-out and should not pay a brown farmer who wants to 'buy' reputation (see e.g., Bénabou and Tirole 2006; Ariely et al. 2009; Bowles and Hwang 2008; Banerjee and Shogren 2012; Arce 2013).

However, this standard mechanism may fail to engage the 'green' farmer as it provides no public recognition for this farmer's conservation activities-relative reputation matters too (Ellingsen and Johannesson 2008; Vesterlund 2003; Bénabou and Tirole 2011). Second, it does not necessarily ensure an increase in ecological outcomes for 'green' farms. A 'green' farmer may not have the appropriate knowledge to enhance conservation further despite being truly green and motivated. To address these two issues, our mechanism incorporates a social reward with a facilitative service. Social rewards without any monetary element, are visible, provide social recognition, and help improve self-esteem (see Frey 2006). Moreover, social rewards work in the competitive environment of a tournament with winners or losers at the end. Everyone in the particular environment knows that the award exists and that winners are typically honoured in a public ceremony. This makes it a powerful motivation as is well-known from the literature on labour economics (see Lacetera and Macis 2010; Kosfeld and Neckermann 2011). We consider a social reward along the facilitation service as a status incentive in our model.

The social award would be in the form of publicity at the national level combined with the invitation to a specialised, environmental leadership program to work closely with professional and highly motivated facilitators to further improve the conservation practices on the individual farm. ${ }^{3}$ The environmental leadership program would be highly selective and available to the green farmers only giving them the opportunity for social esteem. At the same time such an initiative could also help to move greenways the descriptive norm (i.e., what most farmers do). Farmers are trained in agricultural production and have seldom experienced specific training or education in environmental management. Yet managing land for environmental outcomes requires a different set of skills and knowledge (Batáry et al. 2015).

We design a menu of contracts that offers monetary incentives and non-monetary incentives (i.e., facilitation service with social reward) to induce both type of farmers to join the scheme and to take the optimal biodiversity protection action on the farmland (i.e., equivalent to the optimal action under symmetric information). In other words, our menu of contracts offers incentive compatible monetary and non-monetary incentives for different types of farmers keeping their action level at the symmetric information optimal action level in the contract. Results show that in the presence of asymmetric information, a regulator can implement the symmetric information optimal level of biodiversity protection action in both cases by offering a menu of monetary contracts without and with facilitation service and social reward. In the first case, a green-farmer selects the optimal level (i.e., the same as in the complete information case) of monetary compensation and a brown-farmer extracts information rent. In the latter case, a green farmer receives a social reward only (i.e., no monetary payments) whereas the brown-farmer extracts information rents. In the latter case, more public good is created in the equilibrium and the regulator pays out less monetary compensation.

The paper is organized as follows. Section 2 provides the institutional background to our analysis. In Sect. 3, we present the empirical work to support the assumptions underlying our proposed policy design in Sect. 4. The concluding Sect. 5 discusses the main insights

\footnotetext{
3 Examples of such 'farmer of the year' awards combined with invitation to a leadership program do exist, commonly with a focus on strategic and innovation management rather than environmental management. See for example www.farmeroftheyear.com.au/2020/en/page/home.
} 
and the policy implications with reference to the debate on the post-2020 reform of the Common Agricultural Policy in the EU.

\section{Background}

It is well-known that effective design of voluntary agri-environmental schemes aimed at the production of public goods poses real challenges, because of information gaps regarding both private costs and social benefits and because of the voluntary nature of the schemes. These schemes involve individual multi-year contracts signed with farmers who volunteer to implement pro-environmental practices in return for an annual payment. Agrienvironmental schemes share with all voluntary programs the potential for large adverse selection. ${ }^{4}$ Usually, all farmers receive the payment for specific approved practices which reflects income foregone plus additional costs both determined as an average at the national level. Such a flat-rate scheme ignores the heterogeneity among eligible farmers. A conservation auction, which is also an incentive compatible mechanism, can help resolve the inefficiency due to asymmetric information. However, these mechanisms are rarely applied in the practice of conservation contracting in the EU and UK, which is the focus of our paper.

Furthermore, the current design principles and theoretical approaches ${ }^{5}$ in the extant literature assume that farmers adopt a pure economic rationale when deciding about environmental management; they do not consider the fact that farmers may obtain non-monetary satisfaction and social recognition through their management practices. By the nature of their profession, however, farmers are open to the direct, uninvited and unavoidable scrutiny of the peer group. A farmer selecting conservation activities on farmland signals, by construction, his social preferences to other farmers or significant others who are able to observe the implemented conservation practices, such as friends and family, or to the retrospective future self to bolster self-perception. Individuals who care about their social image or reputation behave differently when their actions and choices can be observed by others-with more pro-social or intrinsic behaviour in public than private settings, i.e., an audience effect (e.g., Bénabou and Tirole 2006; Ariely et al. 2009; Andreoni and Bernheim 2009). Those farmers that value reputation will derive utility from the social esteem ${ }^{6}$ associated with their visible conservation activities, conditional on these activities yielding a positive image (see Ellingsen and Johannesson 2008). Thus, taking up a pro-social activity like conservation management of farmland may not be based on pure altruism.

The relevance of social image is confirmed in the literature (Dessart et al. 2019). For example, Kuhfuss et al. (2016) show in a choice experiment that almost half of the French farmers in their study were willing to maintain contracted conservation practices after the end of the contract payment and that information about what other farmers intended to do (the social norm) influenced their own decision. The specific experiment concerned conservation practices that require setting land aside from production. Such options usually create significant and long-lasting opportunity costs for participants in terms of the net value of production foregone. The results from Kuhfuss et al. (2016) suggest that for

\footnotetext{
4 There is ample evidence that the ecological results are largely underwhelming (Batáry et al. 2015).

5 Several policy mechanisms have been proposed in the literature to address the information asymmetry in this specific context. For a recent overview see Latacz-Lohmann and Breustedt (2019, p. 496).

6 We use 'esteem' (and 'disesteem') as this is defined in economic terms by Brennan and Pettit (2004). Words like social approval, prestige and respect would have almost the same meaning (see Ellingsen and Johannesson 2008).
} 
farmers that value reputation, the increase in the signalling value counteracted the effect of the lost payment, in effect crowding-in reputational motives.

Moreover, our mechanism design is closely based on what we observed in voluntary conservation management in U.K. agriculture, specifically regarding the Campaign for the Farmed Environment (CFE). The CFE was launched by the farming organisations in 2009. Initially the CFE's aim was maintaining the environmental benefits provided by former set-aside regulations (15\% later $10 \%$ of land). Set-aside had become compulsory in 1992 for large arable farmers as part of the EU's CAP. Following the 2005 CAP reform this restriction was removed. The delivery ${ }^{7}$ of the CFE program as such was at the local (county) level through local county coordinators working with local liaison groups made up of farmers and representatives of partner organizations. A wide range of survey data has evaluated the CFE (see Mills et al. 2018). For example, it was found that during the 2013/2014 crop year, 44\% of holdings in England had land within one of the 22 CFE-listed unpaid voluntary measures. This totalled to 450 thousand hectares (with an additional 9800 skylark plots and $7400 \mathrm{~km}$ of fenced watercourses). Overall, $38 \%$ of the participating holdings were not involved in any payment scheme in 2014. Given that an attribute of conservation management on farmland is that it involves some sacrifice of financial profit, the CFE results strongly suggest other, non-monetary, motives.

\section{Motivation}

To motivate our model, we first present results from empirical work which included (1) an incentivized survey to understand personal and social norms, and (2) a contingent valuation choice experiment to elicit farmers' WTP for more publicity of their conservation activities. Survey participants were from the Scottish Highlands. ${ }^{8}$ The survey questionnaire was completed by 123 respondents during the summer of $2018 .^{9}$ The questionnaire is included as Appendix A (available online).

Following Krupka and Weber (2013), individual farmers in the incentivized survey played a pure matching coordination game. The participants were asked to rate the level of social acceptability of a hypothetical farmer's actions in a hypothetical scenario. This hypothetical farmer finds an endangered species on his/her private land and there is a significant cost of protecting it. The hypothetical farmer can make three alternative choices: (1) no action; (2) swift action; and (3) asking for funding upfront. The respondents were asked about the socially acceptability of the farmer's choice (on a 5-point Likert-scale ranging from 'very socially acceptable' to 'very socially unacceptable'). Respondents were informed that the person whose answer is the closest match to the median response is

\footnotetext{
7 CFE communications included a website, Campaign leaflets and brochures, CFE led events, as well as a visible presence at a wide range of national, regional and local events operated by partner organizations.

8 They were approached through the Highlands and Islands Farming community in Nairn, near Inverness. The surrounding areas of Inverness and Nairn are some of the densest areas in both population and active farmland in the highlands. Through personal connection, senior individuals in the Highland and Island farming community used member email lists to send invitations to potential participants. The participants are therefore self-selected individuals who responded to a call out from senior individuals in the Highlands and Islands farming community.

9 The survey questionnaire was piloted to a trial group $(\mathrm{N}=10)$ from the target population and was edited based on the feedback received before it was used for the final study $(\mathrm{N}=123)$. All participants completed the same survey either online or on paper. Each participant was paid $£ 8$ as a compensation for their time. Average time of completion was $12 \mathrm{~min}$. The online aspect of the paper was completed on Type-form, an interactive online software, which suited the needs of the analysis perfectly.
} 
rewarded with $£ 50$ - a substantial incentive. This, in theory, invites the participants to consider and match their answers to that of the farming community. Consequently, this consideration of belief how others in the group judge a behaviour and the matching technique will yield an estimate of the social norms surrounding bio-diversity protection (see also Reuben and Riedl 2013; Kimbrough and Vostroknutov 2016).

The results in Table 1 show that based on $t$-tests, we find that 'swift action' is considered significantly better than the other two actions and that 'asking for funds upfront' is a significantly better option than 'do nothing'. This suggests the existence of a social norm surrounding protection of biodiversity among farmers, since they believe it socially desirable to take 'swift action' to protect an endangered species found on private land.

The choice experiment was developed based on an existing Scottish scheme which targets farmers with suckler herds to become as efficient as possible (to reduce emissions). The payment of the beef efficiency scheme was to cover transition costs between old farming practices and new farming practices and to compensate labour costs of transition and implementation. ${ }^{10}$ The monetary values used in the choice experiment were based around the amount currently offered by the Scottish Government for this scheme-approximately $£ 42$ per acre or $£ 32$ per calf. The choice of the other attributes and attribute levels was based on the related literature. Scheme flexibility is arguably the most important issue with the schemes which led us to include three flexibility related attributes. Payment before or after also seemed important to include, especially for small family owned farms who cannot afford upfront the initial costs themselves. Time spent on the scheme was included for obvious reasons.

We used a Mixed Logit Model which allows (1) the coefficients associated with each observed scheme characteristic including the monetary attribute to vary randomly across individuals; and (2) to estimate how the farmers trade off different scheme attributes (e.g., how they traded off attributes such as length of contract for our proxy for publicity seeking - the signpost of recognition). See Appendix A for more details. The inclusion of payment as a scheme attribute enables calculating the marginal rate of substitutions (MRS) between scheme attributes and money. We can then interpret the ratios as marginal willingness to pay/accept (WTP/WTA) for a change in a scheme attribute. ${ }^{11}$ Positive values indicate

\footnotetext{
10 The European Rural Development Regulation, constrained by WTO rules, prescribes that payment for these practices must be no more than the income forgone plus the additional costs incurred from undertaking environmental management. In practice, scheme payments are calculated using national average grossmargin figures with average commodity/input price forecasts for the next 5 year.

11 There are two issues here as a reviewer reminded us. The first issue is that to analyse participation in a proposed biodiversity conservation program both the WTA (receiving compensation for a loss or for not receiving a benefit) and WTP format (paying something for a foregone gain or to obtain a future benefit) may be used. Considering property rights, it is more obvious to ask farmers the minimum compensation that would repay the (income) loss than the maximum WTP to prevent conservation practices on their farm. Biodiversity production competes with commodity production and this suggests that conceptually the WTA format is the correct measure. The virtual price should take account of supply conditions, which reflect the direct and opportunity cost of producing the non-market goods (see Wossink and van Wenum 2003, p. 464). Our CE is set up in line with this reasoning. The second issue is the interpretation of the trade-off between the attributes and the attribute levels based on farmers' responses. Given that we elicit farmers' minimum WTA we can derive how contract elements are valued. The inclusion of payment as a scheme attribute enables calculating the marginal rate of substitutions (MRS) between scheme attributes and money. The farmer could be seen as willing to accept the contract for less money thanks to the attribute (lower WTA) or could be seen to be willing to pay to have the attribute - in relation to the basic contract. It could be interpreted either way. We have left it as a WTP value in alignment with Rutto and Garrod (2009) but note that for example Vaissière et al. (2018) term the MRS as a WTA.
} 


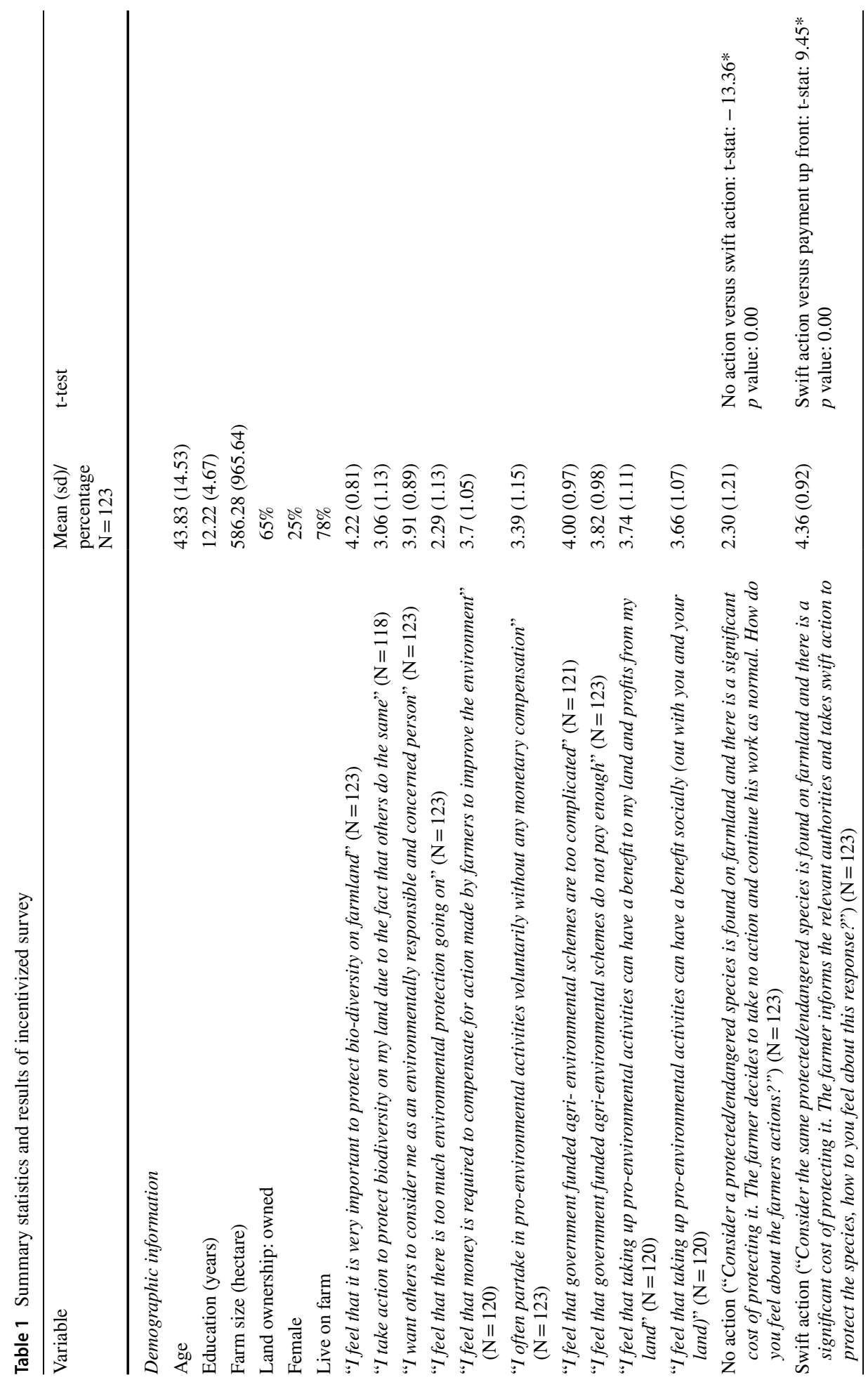




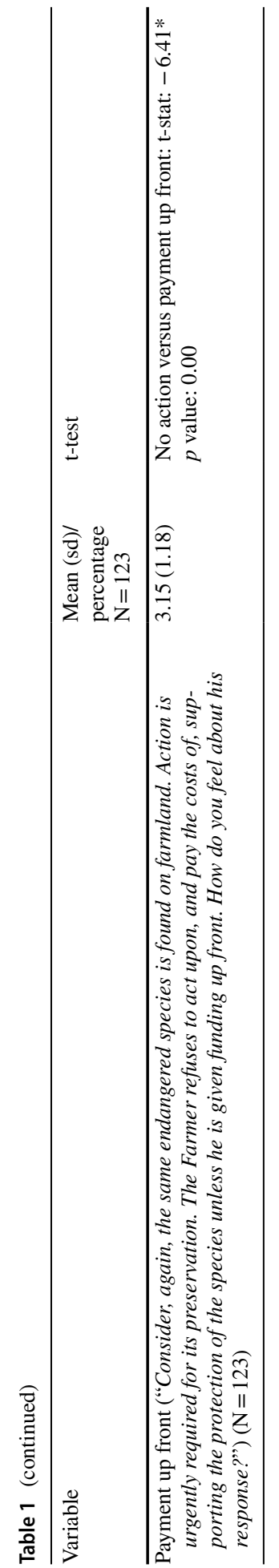

型 Springer 
the increase in per acre payments the landowner would be willing to forego in anticipation of gaining said scheme attribute (see e.g., Ruto and Garrod 2009; Vaissière et al. 2018).

The attributes and attribute levels as used in the choice experiment are highlighted in Table 2 . The survey included a logic jump ${ }^{12}$ in which only participants who had experience raising cattle would answer the choice experiment questions - this was the large majority $(87 \%)$. Individual farmers were faced with two choice cards which depicted different schemes and were asked to choose the response which would satisfy them the most. They were also presented with a neither option and invited to comment on why neither of the schemes interested them. ${ }^{13}$

The utility parameters for all AES parameters as well as the price attribute were set as random with the assumption of a normal distribution. For model specification and testing 50 Halton draws were used. For the final model 1000 Halton draws were used.

All the estimates for the scheme attributes were significant at the 5\% level apart from the payment attribute (whether payment was received up front or not-not the actual monetary payment to receive) (Table 3 ). The results are intuitive and align well with similar experiments run in the past. Since the scheme payment was defined in terms of per acre payments, the calculated monetary values for the other attributes are consequently per acre of land (Table 4).

Intuitively, landowners want shorter contracts and are willing to forgo scheme income to avoid such longer contracts (roughly $£ 1.80$ per acre to avoid an extra year on a contract). Landowners, similarly, also unsurprisingly, do not want to work longer hours on the scheme and are willing to forego around $£ 1.54$ per acre to avoid one extra hour worked per week. Individuals did however positively value both the ability to choose the land area enrolled and the right to be more flexible within the scheme (£9.06 and $£ 9.17$ per acre, respectively).

Most importantly, we can see that individuals do value positively the signpost of recognition. The $p$ value of the result was 0.034 suggesting it is confidently significant at the $5 \%$ level and with more Halton draws we would expect this to decrease further. Individuals were willing to pay $£ 3.85$ per acre to achieve public recognition of their pro-environmental endeavours. Of course, the motivation behind this cannot be completely deduced and it may vary by individual. However, farmers enrolling in AES schemes do value their proenvironmental reputation significantly and are willing to forego payment to enhance this reputation irrelevant of their motivation for desiring an enhanced reputation. This result provided motivation for the model constructed in the following section.

\footnotetext{
12 A logic jump is a survey technique in which logic is designed to automatically skip questions based on their previous answers. For example, if one individual were asked if they had livestock on their farm and they answered no, they would not be asked what type of livestock. However, someone who answered yes would be asked this latter question. Or, if a participant stated that he had never heard of AES schemes the logic jump would foreword him to the next section and not ask them their perceptions about the schemes. This saves time for participants and helps reduce participant fatigue in the interest of extracting the most detailed and accurate answers.

13 This was included solely to try and understand the issues facing farmers in a deeper and more qualitative level to compliment the qualitative analysis and highlight any scheme aspects or issues we may be missing.
} 


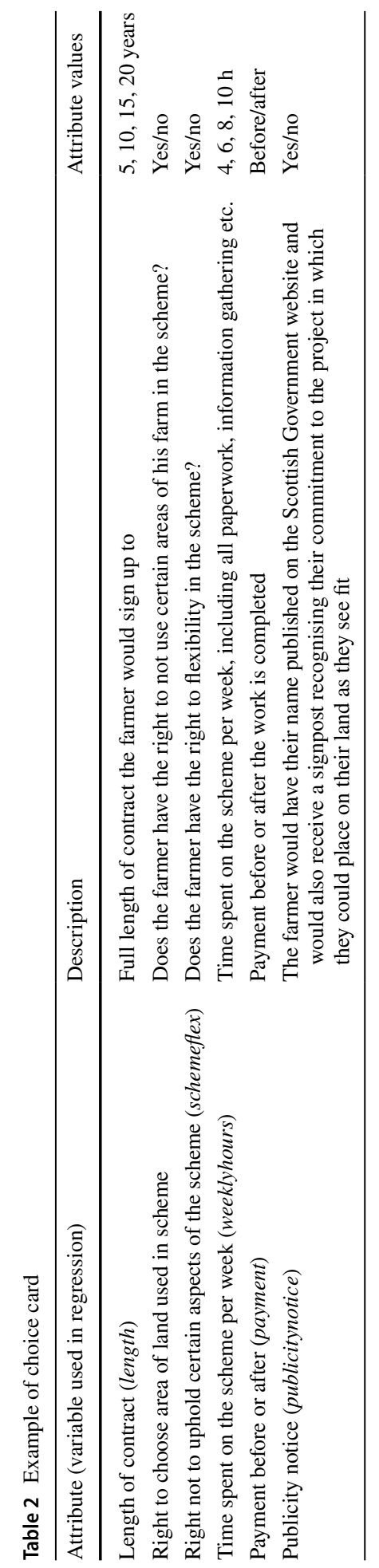


Table 3 Mixed logit results

\begin{tabular}{lcc}
\hline Choice & Coef. $(p$ value $)$ & Coef - SD $(p$ value $)$ \\
\hline Landarea & $0.993(0.000)$ & $1.257(0.000)$ \\
Length & $-0.197(0.000)$ & $0.156(0.000)$ \\
Weeklyhours & $-0.168(0.000)$ & $-0.200(0.000)$ \\
Payment & $-0.192(0.271)$ & $0.575(0.000)$ \\
Schemeflex & $1.005(0.000)$ & $-0.622(0.060)$ \\
Publicitynotice & $0.422(0.025)$ & $-1.341(0.000)$ \\
Price & $0.110(0.00)$ & $1.341(0.000)$ \\
\hline
\end{tabular}

Number of obs $=3690, \quad$ LR $\quad \mathrm{chi}^{2}=809.04, \quad$ Prob $>\mathrm{chi}^{2}=0.0000$, $\mathrm{LL}=-846.8019$. Farm size was grouped into three distinct categories: small land area (i.e., SFlandarea): less than 231 acres; medium land area (MFlandarea): 231-1421 acres; and large land area (i.e., LFlandarea): greater than 1421 acres. These categories were outlined by the standards set by the Scottish Farming association classification. The sign of the estimated standard deviations is irrelevant, please interpret them as being positive

Table 4 WTP estimates

\begin{tabular}{lrlrl}
\hline Choice & \multicolumn{1}{l}{ Coef. } & \multicolumn{1}{l}{ SE } & \multicolumn{1}{l}{$Z$} & $P>|Z|$ \\
\hline Landarea & 9.056 & 2.274 & 3.98 & $0.000^{* * *}$ \\
Length & -1.800 & 0.266 & -6.75 & $0.000^{* * *}$ \\
Weeklyhours & -1.536 & 0.409 & -3.76 & $0.000^{* * *}$ \\
Payment & -1.753 & 1.621 & -1.08 & 0.280 \\
Schemeflex & 9.168 & 1.920 & 4.77 & $0.000^{* * *}$ \\
Publicitynotice & 3.849 & 1.818 & 2.12 & $0.034 * *$ \\
\hline
\end{tabular}

\section{Mechanism with Facilitation and Social Reward}

Herein we develop a voluntary incentive contract to improve ecological outcomes of farmland at less cost considering reputation concerned farmers by using facilitation service and social reward in the presence of adverse selection.

The farmer is a utility maximizing agent, who gets utility from the amount of environmental public good produced from his private action and monetary transfer received from the regulator for his action. A farmer enjoys intrinsic satisfaction from taking private action to produce the public good on the farmland and also gets intrinsic satisfaction when he receives monetary compensation (see Bénabou and Tirole 2006). Based on a farmer's relative importance of his intrinsic preferences for biodiversity protection and his intrinsic valuation for monetary payments for his action, we consider that a farmer can be one of two types-green (G) or brown (B). The green farmer's intrinsic relative valuation for public good creation vis-à-vis monetary transfer received from the regulator for undertaking biodiversity protection action is higher than that of the brown farmer. Normalizing the farmer's intrinsic valuation for public good creation to be equal to one regardless of his type, it implies that a green farmer's intrinsic valuation 
for monetary transfer from the regulator (denoted by $\vartheta^{\mathrm{G}}$ ) is less than that of a brown farmer (denoted by $\vartheta^{\mathrm{B}}$ ): $0<\vartheta^{\mathrm{G}}<\vartheta^{\mathrm{B}}$. ${ }^{14}$

The farmer's type is his private information: nature decides a farmer's type- $G$ or $B$. The regulator and other people in the society have identical prior beliefs regarding the type of the farmer: a green-type with probability $\rho(0<\rho<1)$ and brown-type with probability $1-\rho$. Let $x^{i}(\geq 0)$ denote biodiversity protection action undertaken by the farmer of type $(i(=G, B)) .{ }^{15}$ Both type of farmers care about social reputation, and the green farmer takes greater interest in utilizing any services offered to protect biodiversity on his farmland (e.g., facilitation services). The challenge for the regulator is to design the contract that could separate the types out so that each type gets their appropriate incentives.

In standard adverse selection problems, it is assumed that each type self-selects the contract specified for him and acts accordingly (as it is incentive compatible to do so). This means that it is implicitly assumed that the regulator can verify the actions specified in the contract. In case of biodiversity protection actions, however, actions can be observable, but it might be sufficiently costly to verify the actions. We explore here, in the presence of asymmetric information about the two type of farmer, how to design a menu of incentive compatible contracts by using monetary and non-monetary incentives to implement the optimal symmetric equilibrium level of action even when actions are not verifiable.

In absence of any facilitation services, the type $i$ farmer produces $g\left(x^{i}\right)$ amount of public good. Under facilitation, $f^{i}\left(x^{i}\right)$ amount of public good is produced. A green farmer is intrinsically motivated to protect the environment, and given facilitation services, his action leads to a higher amount of public good generation, for any given action $x^{G}>0$. It is well documented in the literature that people are heterogeneous in types-some people are more intrinsically motivated than others - and intrinsically motived people tend to contribute more to a public good (see e.g., Besley and Ghatak 2008; Fehr and Leibbrandt 2011; Ashraf et al. 2014; Carpenter and Seki 2011). The brown farmer may also produce more public good when his action is facilitated compared to that in absence of facilitation, however, the extent of the increase (if any) in public good creation due to facilitation services is less than that by the green farmer (Assumption 1(b)).

\section{Assumption 1}

(a) Functions $g\left(x^{i}\right)$ and $f^{i}\left(x^{i}\right)$ are continuous, twice differentiable and concave in $x^{i}(\geq 0)$ : $g(0)=f^{i}(0)=0 ; g^{\prime}\left(x^{i}\right)>0, g^{\prime \prime}\left(x^{i}\right)<0, f^{i^{\prime}}\left(x^{i}\right)>0$ and $f^{i^{\prime \prime}}\left(x^{i}\right)<0 \forall x^{i} \geq 0 ; i=G, B$. (b) $g(x) \leq f^{B}(x)<f^{G}(x)$ for any given $x>0$.

If the farmer's biodiversity protection action is facilitated by the regulator, the regulator offers him some non-monetary incentives, such as an invitation to join an expert opinion/ information program, as well as offering monetary compensation $t_{F}(\geq 0)$, where subscript

\footnotetext{
14 Alternatively, if we consider that the farmer's intrinsic valuation for monetary transfer received for protecting biodiversity on his farmland does not depend on his type, but the green farmer's intrinsic valuation for public good creation is greater than that of the brown farmer, qualitative results of this analysis go through.

15 It is possible that observations of farmers' management actions and of the biodiversity productions come with an error term. We assume that action (and production of public good) is certain. Future research could explore the possibility of adding uncertainty to the model.
} 
$F$ indicates 'facilitation'. Otherwise, the regulator offers the farmer only monetary compensation $t_{N}(\geq 0)$, where subscript $N$ indicates 'no facilitation'.

The farmer gains social reputation if fellow members in the society perceive him as green and doing the right thing, but not for money. Non-monetary incentives, such as social reward, further augment farmer's social reputation and that may in turn enhance his motivation for public goods creation (see e.g., Besley and Ghatak 2008; Frey 2006; Kosfeld and Neckermann 2011). ${ }^{16}$ In line with Bénabou and Tirole (2006), we consider that the type $i(=G, B)$ farmer's social reputation function is as follows.

$$
R^{i}=R\left(E\left(\vartheta \mid x^{i}, t^{i}\right), x^{i} ; \theta\right),
$$

where $E\left(\vartheta \mid x^{i}, t^{i}\right)$ is the expected value of type $i$ farmer's intrinsic valuation for money given the biodiversity protection action $\left(x^{i}\right)$ undertaken by him and monetary compensation $\left(t^{i}\right)$ received by him for this action and $\theta \in\left\{\theta_{F}, \theta_{N}\right\}, 0 \leq \theta_{N}<\theta_{F}$, is a reputation parameter. $\theta=\theta_{F}$ (resp. $\theta=\theta_{N}$ ) corresponds to the case in which the farmer receives (resp. does not get) the social reward.

Assumption $2 R\left(E\left(\vartheta \mid x^{i}, t^{i}\right), x^{i} ; \theta\right)$ is continuous and twice differentiable function in $E\left(\vartheta \mid x^{i}, t^{i}\right) \in\left[\vartheta^{G}, \vartheta^{B}\right]$ and $x^{i} \geq 0$, such that the following properties are satisfied for all $i=G, B$.

$\begin{array}{ll}\text { (a) } \frac{\partial R\left(E\left(\vartheta \mid x^{i}, t^{i}\right), x^{i} ; \theta\right)}{\partial E\left(\vartheta \mid x^{i}, t^{i}\right)}<0, \quad \frac{\partial R\left(E\left(\vartheta \mid x^{i}, t^{i}\right), x^{i} ; \theta\right)}{\partial x^{i}} \geq 0, \quad \frac{\partial}{\partial x^{i}}\left[\frac{\partial R\left(E\left(\vartheta \mid x^{i}, t^{i}\right), x^{i} ; \theta\right)}{\partial x^{i}}\right] \leq 0 \quad \text { a n d } \\ & \frac{\partial}{\partial E\left(\vartheta \mid x^{i}, t^{i}\right)}\left[\frac{\partial R\left(E\left(\vartheta \mid x^{i}, t^{i}\right), x^{i} ; \theta\right)}{\partial x^{i}}\right] \leq 0 . \\ \text { (b) } \Delta_{\theta} R>0, \frac{\partial\left(\Delta_{\theta} R\right)}{\partial E\left(\vartheta \mid x^{i}, t^{i}\right)} \leq 0, \quad \frac{\partial\left(\Delta_{\theta} R\right)}{\partial x^{i}} \geq 0 \quad \text { and } \quad \frac{\partial}{\partial E\left(\vartheta \mid x^{i}, t^{i}\right)}\left(\frac{\partial\left(\Delta_{\theta} R\right)}{\partial x^{i}}\right) \leq 0 ; & \text { wh e r e } \\ & \Delta_{\theta} R=R\left(E\left(\vartheta \mid x^{i}, t^{i}\right), x^{i} ; \theta_{F}\right)-R\left(E\left(\vartheta \mid x^{i}, t^{i}\right), x^{i} ; \theta_{N}\right) \text { and } 0 \leq \theta_{N}<\theta_{F} .\end{array}$

Assumption 2 implies that, under complete information (i.e., $E\left(\vartheta \mid x^{i}, t^{i}\right)=\vartheta^{i}$, $i=G, B)$, (i) a green farmer enjoys strictly higher social reputation than a brown farmer, unless the former undertakes less biodiversity protection action than the latter (i.e., $R\left(\vartheta^{G}, x^{G} ; \theta\right)>R\left(\vartheta^{B}, x^{B} ; \theta\right)>0, \forall x^{G} \geq x^{B}$ and $\left.\theta \in\left\{\theta_{F}, \theta_{N}\right\}\right)$, and, (ii) due to an increase in his action from any given level, the increment in social reputation of the green farmer is at least as large as that of the brown farmer, regardless of whether the regulator offers him non-monetary incentives or not (i.e., $\frac{\partial R\left(\vartheta^{G}, x ; \theta\right)}{\partial x} \geq \frac{\partial R\left(\vartheta^{B}, x ; \theta\right)}{\partial x} \geq 0$ for any $\theta \in\left\{\theta_{F}, \theta_{N}\right\}$ ). ${ }^{17}$ For simplicity, we assume that the farmer's social reputation is increasing at a nonincreasing rate with his biodiversity protection action (Assumption 2(a)). Assumption 2(a) also implies that, the higher is the expectation regarding the farmer's relative valuation for public good creation vis-à-vis monetary transfer received from the regulator (i.e., the lower is the $E\left(\vartheta \mid x^{i}, t^{i}\right)$ ), the higher is the marginal positive effect of the farmer's biodiversity protection action on his social reputation. $\frac{\partial R\left(E\left(\vartheta \mid x^{i}, t^{i}\right), x^{i} ; \theta\right)}{\partial x^{i}}=0$ corresponds to the specific case

\footnotetext{
${ }^{16}$ Besley and Ghatak (2008) argue that status incentives, such as tokens, medals, can increase effort, even when effort is not observable. Fehr and Schmidt (1999) also emphasize the role of relative rewards.

${ }^{17}$ Note that, unlike Bénabou and Tirole (2006), the above formulation of the reputation function allows for farmers' reputation to be directly dependent, not only on conditional expectation of his intrinsic valuation of monetary compensation based on his action and monetary transfer, but also on his behaviour towards the environment. We mention here that the results of this analysis go through, if we consider that social reputation depends on public good produced by the farmer, instead of his action, if higher action produces more public good.
} 
in which reputation solely depends on the expected value of the farmer's intrinsic valuation for money and on whether the farmer received social award for undertaking biodiversity protection action, but does not directly depend on the farmers' biodiversity protection action.

Assumption 2(b) implies that, for any given $E\left(\vartheta \mid x^{i}, t^{i}\right)$ and $x^{i}$, non-monetary incentives (e.g., social reward) enhance a farmer's social reputation regardless of his type. However, such reputation augmenting effect of non-monetary incentive is higher, if (a) others perceive that the farmer has lower intrinsic valuation of money and/or (b) the farmer undertakes higher biodiversity protection action. It follows that, for any given biodiversity protection action, the value of the social reward to a brown farmer is much less than that to a green framer, when a farmer's true type is known to all. The rationale is the following. A farmer enjoys intrinsic satisfaction from gaining a 'green' social reputation which depends on observers' posterior beliefs of the farmer's true intrinsic valuation for money given monetary transfer and his efforts (as argued by Bénabou and Tirole 2006). In addition, a social reward provides higher value through, e.g., greater visibility and social recognition and helps to increase the effort of an individual by enhancing their self-esteem and social recognition (Lacetera and Macis 2010; Kosfeld and Neckermann 2011).

The utility of a farmer of type $i(=G, B)$ is assumed to be as follows.

$$
U^{i}=\left\{\begin{array}{l}
U_{F}^{i}\left(x^{i}, t_{F}^{i}\right)=f^{i}\left(x^{i}\right)+\vartheta^{i} t_{F}^{i}-C\left(x^{i}\right)+R\left(E\left(\vartheta \mid x^{i}, t^{i}\right), x^{i} ; \theta_{F}\right) \\
U_{N}^{i}\left(x^{i}, t_{N}^{i}\right)=g\left(x^{i}\right)+\vartheta^{i} t_{N}^{i}-C\left(x^{i}\right)+R\left(E\left(\vartheta \mid x^{i}, t^{i}\right), x^{i} ; \theta_{N}\right)
\end{array}\right.
$$

where $U_{F}^{i}\left(x^{i}, t_{F}^{i}\right)$ is the utility of the type $i$ farmer when the regulator facilitates his action and offers him monetary compensation $t_{F}^{i}, U_{N}^{i}\left(x^{i}, t_{N}^{i}\right)$ is the utility of the type $i$ farmer when the regulator does not facilitate his action and offers him monetary compensation $t_{N}^{i}$. $C\left(x^{i}\right)$ denote the cost of undertaking biodiversity protection action.

Assumption 3 (i) For all $x^{i} \geq 0, f^{G^{\prime}}(x)>f^{B^{\prime}}(x) \geq g^{\prime}(x)>0, f^{G^{\prime \prime}}(x)<0, f^{B^{\prime \prime}}(x)<0$ and $g^{\prime \prime}<0$ and (c) $C^{\prime}>0$ and $C^{\prime \prime} \geq 0$. (ii) $U_{j}^{i}(0,0)=0$ and $\left.\frac{\partial U_{j}^{i}\left(x^{i}, t_{j}^{i}\right)}{\partial x^{i}}\right|_{x^{i}=0}>0, j=F, N$.

Assumptions $1 \& 3$ imply that facilitation of the green farmer's biodiversity protection action better serves the environment, as he cares more about the environment than does the brown farmer. Further, Assumptions 1-3 imply that both $U_{F}^{i}\left(x^{i}, t_{F}^{i}\right)$ and $U_{N}^{i}\left(x^{i}, t_{N}^{i}\right)$ are strictly concave in $x^{i}$.

We define the net social benefit from biodiversity protection in farmland as

$$
W_{j}=W(y, \tau, I),
$$

where $y(\geq 0)$ denotes the amount of public good produced by the farmer, $\tau$ denotes the monetary compensation offered to the farmer and $I(\geq 0)$ denotes the amount of public resources utilized to provide facilitation services to the farmer. We consider that it is necessary to spend $I(>0)$ of public resources to facilitate a farmer's biodiversity protection action, regardless of the farmer's type-green or brown. The net social benefit function satisfies the following properties:

Assumption 4 (i) $W_{j}=W(y, \tau, I)$ is continuously differentiable in its arguments, strictly increasing in $y \geq 0$, and strictly decreasing in both $\tau \geq 0$ and $I \geq 0$; and (ii) $W(0,0,0)=0$. 
The regulator decides to facilitate the farmer's action only if the net social benefit of doing so exceeds the threshold level $\underline{W}$, where $\underline{W}$ is the net social benefit from alternative utilization of public resources $(I)$ required to facilitate the farmer's biodiversity protection action, i.e., the opportunity cost of public resources $I$.

\subsection{Symmetric Information}

Under symmetric information, the farmer's type is common knowledge (i.e., $\left.E\left(\vartheta \mid x_{1}^{i}, t_{1}^{i}\right)=\vartheta^{i}\right)$. In this case, ignoring farmers' participation constraints, the problem of type $i$ farmer, if the regulator facilitates his biodiversity protection action and offers monetary compensation $t_{F}^{i}$, can be written as follows.

$$
\operatorname{Max}_{x^{i}} U_{F}^{i}\left(x^{i}, t_{F}^{i}\right)=f^{i}\left(x^{i}\right)+\vartheta^{i} t_{F}^{i}-C\left(x^{i}\right)+R\left(\vartheta^{i}, x^{i} ; \theta_{F}\right) ; \quad i=G, B .
$$

The first order condition of problem (3) is as follows.

$$
\frac{\partial U_{F}^{i}}{\partial x^{i}}=f^{i^{\prime}}-C^{\prime}+\frac{\partial R\left(\vartheta^{i}, x^{i} ; \theta_{F}\right)}{\partial x^{i}}=0 ; \quad i=G, B .
$$

The second order condition for maximization $\left(\frac{\partial^{2} U_{F}^{i}}{\partial x^{i}}<0\right)$ is satisfied, since $U_{F}^{i}($.$) is strictly$ concave in $x^{i}$. Solving Eq. (4) we get the optimum choice of type $i$ farmer when his biodiversity protection action is facilitated by the regulator.

Definition 1 Let $x_{F}^{i *}=\operatorname{argmax}_{x^{i}} U_{F}^{i}\left(x^{i}, t_{F}^{i}\right), i=G, B$.

Lemma 1 Suppose that Assumptions 1-4 hold true. Then, $x_{F}^{G *}>x_{F}^{B *}>0$ and $f^{G}\left(x_{F}^{G *}\right)>f^{B}\left(x_{F}^{B *}\right)$.

\section{Proof See Appendix B.}

As shown in Lemma 1, in the equilibrium the green farmer chooses a higher level of biodiversity protection action and produces more public good than the brown farmer, because (a) the green farmer's marginal productivity of biodiversity protection action is higher than that of the brown farmer and (b) the marginal effect of a farmer's biodiversity protection action on his social reputation is non-increasing in expectation regarding his intrinsic valuation of money.

On the other hand, if the regulator does not facilitate his biodiversity protection action and offers monetary compensation $t_{N}^{i}$ to type $i(=G, B)$ farmer, the problem of type $i$ farmer can be written as follows (ignoring his participation constraint).

$$
\max _{x^{i}} U_{N}^{i}\left(x^{i}, t_{N}^{i}\right)=g\left(x^{i}\right)+\vartheta^{i} t_{N}^{i}-C\left(x^{i}\right)+R\left(\vartheta^{i}, x^{i} ; \theta_{N}\right) ; \quad i=G, B .
$$

The first order condition of problem (5) is as follows.

$$
\frac{\partial U_{N}^{i}}{\partial x^{i}}=g^{\prime}-C^{\prime}+\frac{\partial R\left(\vartheta^{i}, x^{i} ; \theta_{N}\right)}{\partial x^{i}}=0 ; \quad i=G, B .
$$

The second order condition for maximization $\left(\frac{\partial^{2} U_{N}^{i}}{\partial x^{i^{2}}}<0\right)$ is satisfied, since $U_{N}^{i}($.$) is$ strictly concave in $x^{i}$. Solving Eq. (6) we get the optimum choice of type $i$ farmer when his biodiversity protection action is not facilitated by the regulator. 
Definition 2 Let $x_{N}^{i *}=\underset{x^{i}}{\operatorname{argmax}} U_{N}^{i}\left(x^{i}, t_{N}^{i}\right), i=G, B$.

Lemma 2 Suppose that Assumptions 1-4 hold true. Then, $x_{N}^{G *} \geq x_{N}^{B *}>0$ and $g\left(x_{N}^{G *}\right) \geq g\left(x_{N}^{B *}\right)$, where the equalities hold true only if $\frac{\partial}{\partial \nu}\left(\frac{\partial R\left(\vartheta, x^{i} ; \theta_{N}\right)}{\partial x^{i}}\right)=0$.

Proof See Appendix B.

Lemma 3 Suppose that Assumptions 1-4 hold true. Then, the following is true.

(a) $x_{F}^{G *}>x_{N}^{G *}$ and $f^{G}\left(x_{F}^{G *}\right)>g\left(x_{N}^{G *}\right)$, and

(b) $x_{F}^{B *} \geq x_{N}^{B *}$ and $f^{B}\left(x_{F}^{B *}\right) \geq g\left(x_{N}^{B *}\right)$, where equalities hold true only if $f^{B}(x)=g(x)$ and $\frac{\partial^{F}}{\partial x}\left[R\left(\vartheta^{B}, x ; \theta_{F}\right)-R\left(\vartheta^{B}, x ; \theta_{N}\right)\right]=0 \forall x \geq 0$.

Proof See Appendix B.

That is, given that the farmer's participation constraint is satisfied, his optimal biodiversity protection action under facilitation is (i) at least equal to his action under no facilitation regardless of the farmer's type; and (ii) if the farmer is G-type, facilitation results in strictly higher level of public goods creation, but not necessarily so in case the farmer is B-type.

Definition 3 Let $t_{N}^{i}$ (resp. $t_{F}^{i}$ ) be the monetary transfers to the type $i$ farmer such that his participation constraint in absence (resp. in presence) of facilitation services is binding, when the farmer chooses his biodiversity protection action optimally: $U_{N}^{i}\left(x_{N}^{i *}, t_{N}^{i}\right)=\underline{U^{i}}$ and $U_{F}^{i}\left(x_{F}^{i *}, t_{F}^{i}\right)=\underline{U^{i}}$, where $\underline{U^{i}}$ is type - $i$ farmer's reservation payoff; $i=G, B$.

Definition 4 Let (a) $\Psi_{N}^{i}=U_{N}^{i}\left(x^{i}\right)-\vartheta^{i} t_{N}^{i} \quad$ and $\quad \Psi_{F}^{i}=U_{F}^{i}\left(x^{i}\right)-\vartheta^{i} t_{F}^{i}$, and $\Psi_{N}^{i *}=U_{N}^{i}\left(x_{N}^{i *}\right)-\vartheta^{i} t_{N}^{i}$ and $\Psi_{F}^{i *}=U_{F}^{i}\left(x_{F}^{i *}\right)-\vartheta^{i} t_{F}^{i} ; i=G, B$.

That is, $\quad \Psi_{N}^{i}=g\left(x^{i}\right)-C\left(x^{i}\right)+R\left(E\left(\vartheta \mid x^{i}, t^{i}\right), x^{i} ; \theta_{N}\right) \quad$ and $\quad \Psi_{F}^{i}=f^{i}\left(x^{i}\right)-C\left(x^{i}\right)+$ $R\left(E\left(\vartheta \mid x^{i}, t^{i}\right), x^{i} ; \theta_{F}\right)$, respectively, are gross utilities (utility without taking monetary transfer into account) of type $i$ farmer in case of no facilitation and in case of facilitation. Correspondingly, $\Psi_{N}^{i *}$ and $\Psi_{F}^{i *}$ are the optimal gross utilities of type $i$ farmer under symmetric information, in absence and presence of any facilitation services; $i=G, B$. From Lemma $1-3$, we get the following.

Lemma 4 Suppose that Assumptions 1-4 hold true. Then, the following is true.

(a) $\Psi_{N}^{i *}<\Psi_{F}^{i *}, i=G, B$

(b) $\Psi_{F}^{G *}>\Psi_{F}^{B *}$ and

(c) $\Psi_{N}^{G *}>\Psi_{N}^{B *}$.

Proof See Appendix B.

Assumption $5 \Psi_{N}^{i *}<\underline{U^{i}}<\Psi_{F}^{i *}, \quad i=G, B$.

Assumption 5 implies that, if the regulator does not offer facilitation services, it is necessary to offer monetary transfers to induce the farmer to undertake biodiversity protection 
action on his farmland, regardless of his type. In contrast, each type of farmer opts to undertake biodiversity protection action even in absence of any monetary transfer, if the regulator facilitates his action. That is, implicitly it is assumed that facilitation services coupled with the social reward lead to sufficient increase in the farmer's social reputation.

Lemma 5 Suppose that Assumptions 1 - 5 hold true. Then under symmetric information, (a) if the regulator does not provide facilitation services to the farmer, it is optimal for the regulator to offer a fixed monetary transfer $t_{N}^{i *}=t_{N}^{i}=\frac{U^{i}-\Psi_{N}^{i *}}{\vartheta^{i}}>0$ to the farmer of type $i$ $(i=G, B)$ and $(b)$ if the regulator facilitates the farmer's biodiversity protection action, it is optimal for the regulator to offer no monetary transfer, $t_{F}^{i *}=t_{F}^{i}=0$, to the farmer regardless of his type. ${ }^{18}$

\section{Proof See Appendix B.}

We consider that it is optimal for the regulator to facilitate biodiversity protection action of the green farmer only. However, the regulator is interested to induce both green and brown farmers to join the scheme. It is optimal to offer only monetary transfer to the brown farmer to induce him to the contract.

\subsection{Asymmetric Information}

In this case, only the farmer knows his true type. Everyone else, including the regulator, knows that the farmer is one of two types-green or brown, but cannot identify the true type of the farmer. As stated before, a farmer is a green-type with probability $\rho$ and a brown-type with probability $1-\rho, 0<\rho<1$. These beliefs are common knowledge.

Monetary rewards may weaken intrinsic motivation due to e.g., the hidden cost of rewards, the over-justification effect, or the corruption effect (see e.g., Bowles 2008). Monetary rewards may reduce the ability to indulge altruistic feelings, or may adversely affect reputation as taking money for a noble work may be seen as 'money hungry' behaviour (Bénabou and Tirole 2006; Ariely et al. 2009; Banerjee and Shogren 2012). In our case, a reputation concerned farmer may reduce his action when given a monetary incentive. Under asymmetric information, solving the farmer's optimisation problem, we get the optimum choice of the farmer when his biodiversity protection action is facilitated by the regulator (this will work even if the regulator does not facilitate a farmer's action). A comparative static result shows the following:

\footnotetext{
${ }^{18}$ Suppose that Assumption 5 does not hold true, instead the following holds $\Psi_{\mathrm{N}}^{\mathrm{B} *}<\Psi_{\mathrm{F}}^{\mathrm{B} *}<\underline{\mathrm{U}^{\mathrm{B}}}$ and $\Psi_{\mathrm{N}}^{\mathrm{G}^{*}}<\mathrm{U}^{\mathrm{B}}<\Psi_{\mathrm{F}}^{\mathrm{G}^{*}}$. Then, under symmetric information, if the regulator does not provide facilitation services to the farmer, the optimal monetary transfer would be the same as in Lemma 5. On the other hand, if the regulator facilitates the farmer's biodiversity protection action, while it is optimal for the regulator to offer no monetary transfer to the green farmer, i.e., $\mathrm{t}_{\mathrm{F}}^{\mathrm{G}^{*}}=\mathrm{t}_{\mathrm{F}}^{\mathrm{G}}=0$, as in Lemma 5, the brown framer needs to be paid the amount $\mathrm{t}_{\mathrm{F}}^{\mathrm{B}^{*}}=\frac{\mathrm{U}^{\mathrm{B}}-\varphi_{\mathrm{F}}^{\mathrm{B}^{*}}}{\vartheta^{\mathrm{B}}}>0$ under symmetric information. Note that $\frac{\mathrm{U}^{\mathrm{B}}-\Psi_{\mathrm{B}}^{\mathrm{B}^{*}}}{\vartheta^{\mathrm{B}}}<t_{\mathrm{N}}^{\mathrm{B}}$, i.e., the regulator needs to pay less to the brown farmer in case his action is facilitated, since facilitation helps him to enhance his social reputation to some extent. Needless to mention here that the equilibrium public good creation will be the same.
} 


$$
\begin{gathered}
\frac{d x^{i}}{d t}=\frac{-\frac{\partial^{2} R\left(E\left(\vartheta \mid x^{i}, t^{i}\right), x^{i} ; \theta_{F}\right)}{\partial x^{i} \partial t}}{\left(f^{i^{\prime \prime}}-C^{\prime \prime}\right)}<0, \\
\text { since } \frac{\partial^{2} R\left(E\left(\vartheta \mid x^{i}, t^{i}\right), x^{i} ; \theta_{F}\right)}{\partial x^{i} \partial t}=\frac{\partial^{2} R\left(E\left(\vartheta \mid x^{i}, t^{i}\right), x^{i} ; \theta_{F}\right)}{\partial x^{i} \partial E\left(\vartheta \mid x^{i}, t^{i}\right)} \frac{\partial E\left(\vartheta \mid x^{i}, t^{i}\right)}{\partial t} \\
\left.<0, \text { and } f^{i^{\prime \prime}}\left\langle 0, C^{\prime \prime}\right\rangle 0 \text { (by Assumption } 2 \text { and } 3\right) .
\end{gathered}
$$

As higher monetary compensation affects reputation adversely, a farmer may reduce actions given monetary compensation, which is similar to the classic reputational crowding out effect (Bénabou and Tirole 2006). Our contract takes care of such crowding out effects by satisfying both types' incentive compatible constraints: the optimal contract shows that the green type takes no money and the brown farmer takes money to exert optimal level of action.

In absence of any additional information regarding the farmer's true type, the expected value of the farmer's intrinsic valuation for money is given by $E(\vartheta \mid x, t)=\rho \vartheta^{G}+(1-\rho) \vartheta^{B}=\bar{\vartheta}$. Then, by Assumption $2, R\left(\vartheta^{B}, x ; \theta\right)<R(\bar{\vartheta}, x ; \theta)<R\left(\vartheta^{G}, x ; \theta\right)$. If the green farmer is unable to credibly signal his true type, he loses social reputation due to asymmetric information. It induces him to take lower biodiversity protection action compared to his symmetric information optimal action (unless the marginal effect of a farmer's action on reputation is independent of the perceived type of that farmer). In contrast, the brown farmer may be able to enjoy higher social reputation by hiding his true type under asymmetric information, and he may also undertake higher level of biodiversity protection action than that under symmetric information.

Note that, under symmetric information, facilitation is beneficial to society if the farmer is of the green-type, but not if the farmer is of the brown-type (as discussed above). However, both the green and brown type farmers are interested in the facilitation offered by the regulator, i.e., to be invited to join the expert opinion/information program on environmental practices and its implementation (Assumption 4). Further, if the regulator offers the menu of contracts $\left\{\left(x^{G *}, t_{F}=0\right),\left(x^{B *}, t_{N}=t_{N}^{B *}\right)\right\}$, i.e., if the regulator offers the menu involving symmetric information optimal contracts, it follows that: (a) the brown farmer will have the incentive to choose the contract $\left(x^{B *}, t_{N}=t_{N}^{B *}\right)$, and (b) the green farmer may not be interested to participate in biodiversity protection activity, since he loses social reputation unless he can credibly signal his true type and signalling may be sufficiently costly. The challenge for the regulator is to design a socially optimal contract under asymmetric information providing appropriate incentive to each type. In such a scenario, the regulator designs a menu of contracts such that, the farmer, green or brown, self-selects the contract meant for him which specifies his action and corresponding incentives (i.e., monetary and/ or non-monetary), and social welfare is maximized.

Now we discuss how a regulator can design monetary incentive contracts without and with facilitation and social reward and we compare the outcomes under these two scenarios.

Case I First suppose that the regulator does not offer any facilitation service or nonmonetary incentive (e.g., social reward), instead the regulator offers a menu of monetary transfers $\left\{x_{N}^{i}, t_{N}^{i}\right\}, i=G, B$, such that the farmer participates in biodiversity protection activity regardless of his type. As a farmer's social reputation depends on fellow citizens' beliefs regarding his intrinsic valuation for money, given his choice of biodiversity protection action and the monetary transfer received by him, he needs to correctly anticipate 
the effects of his choices on his social reputation. To characterize the self-selection equilibrium, if it exists, let us specify the off-the-equilibrium beliefs of fellow citizens as follows. If a combination of biodiversity protection action and monetary $\operatorname{transfer}\left(x^{G * *}, t^{G * *}\right)$ is observed, it is incentive compatible only for the green farmer to choose $x^{G * *}$ level of action for monetary transfer $t^{G * *}$. Otherwise, if any other $(x, t) \neq\left(x^{G * *}, t^{G * *}\right)$ is observed, everyone believes that the farmer is of type $\mathrm{B}$.

Lemma 6 Suppose that Assumptions 1-5 hold true and the regulator offers the menu of contracts $\left\{\left(t_{N}^{G}, N\right),\left(t_{N}^{B}, N\right)\right\}$ where $N$ indicates no non-monetary incentives and $i(=G, B)$ indicates that the contract is meant for the type-i farmer; $t_{N}^{G} \neq t_{N}^{B}$ and $t_{N}^{B}, t_{N}^{G} \geq 0$. Then in the equilibrium under asymmetric information each type of farmers self-selects the contract meant from him as well as chooses his 'symmetric information equilibrium level of biodiversity protection action in absence of any non-monetary incentive', if the following inequalities hold true.

(i) $t_{N}^{B} \geq \frac{U^{B}-\Psi_{N}^{B *}}{\vartheta^{\mathrm{B}}}$,

(ii) $t_{N}^{G} \geq \frac{U^{G}-\Psi_{N}^{G *}}{v^{G}}$ and

$$
\frac{\Psi_{N}^{G *}-\Psi_{N}^{B *}}{v^{B}} \leq t_{N}^{B}-t_{N}^{G}<\frac{\Psi_{N}^{G *}-\Psi_{N}^{B *}}{v^{G}}
$$

(iii)

where $\Psi_{N}^{G *}$ and $\Psi_{N}^{B *}$ are as in Definition 4.

Proof See Appendix B.

Lemma 7 Suppose that Assumptions 1-5 hold true and the regulator does not offer any non-monetary incentives. Then under asymmetric information the regulator can implement the symmetric information equilibrium outcomes, $x_{N}^{G * *}=x_{N}^{G *}$ and $x_{N}^{B * *}=x_{N}^{B *}$, at the least cost by offering the following monetary transfers to each type

$$
t_{N}^{G * *, s}=\frac{U^{G}-\Psi_{N}^{G *}}{\vartheta^{\mathrm{G}}}=\underline{t_{N}^{G}} \text { and } t_{N}^{B * *, s}=\frac{\Psi_{N}^{G *}-\Psi_{N}^{B *}}{v^{B}}+\frac{\frac{U^{G}}{2}-\Psi_{N}^{G *}}{\vartheta^{\mathrm{G}}}>\underline{t_{N}^{B}} \text {, if } \frac{U^{B}-\Psi_{N}^{G *}}{\vartheta^{\mathrm{B}}}<\frac{\frac{U^{G}}{2}-\Psi_{N}^{G *}}{\vartheta^{\mathrm{G}}} .
$$

Proof See Appendix B.

It is easy to show that, if reservation utilities of green and brown farmers are the same, i.e., if $\underline{U^{G}}=\underline{U^{B}}, \frac{U^{B}-\Psi_{N}^{G *}}{\vartheta^{\mathrm{B}}}<\frac{U^{G}-\Psi_{N}^{G *}}{\vartheta^{\mathrm{G}}}$ holds true (since $\vartheta^{\mathrm{G}}<\vartheta^{\mathrm{B}}$ ) and, thus, Lemma 7 is the only possibility. It implies that, when the two types of farmers differ from each other only in terms of their intrinsic valuation for money, under asymmetric information the regulator can implement the symmetric information equilibrium levels of biodiversity protection actions by offering (1) the symmetric information equilibrium amount of monetary transfer to the green farmer and (2) more than the symmetric information equilibrium amount of monetary transfer to the brown farmer, in absence of non-monetary incentives. The same holds true, even if the two farmers have different reservation utilities, provided that the brown farmer's reservation utility is either less than the green farmer's reservation utility $\left(\underline{U^{B}}<\underline{U^{G}}\right)$ or the brown farmer's reservation utility is more than that of the green farmer but less than a critical level $\left(\underline{U^{G}}<\underline{U^{B}}<\underline{U^{G}}+\frac{\left(v^{B}-\vartheta^{\mathrm{G}}\right)\left(\underline{\left.U^{G}-\Psi_{N}^{G *}\right)}\right.}{\vartheta^{\mathrm{G}}}\right)$. This is because, under symmetric information the brown farmer receives lower reputation than the green farmer. When a farmer's type is his private information, the brown farmer has an incentive 
to pretend to be the green farmer. Thus, to induce the brown farmer to be truthful, higher than symmetric information equilibrium monetary transfer to him is necessary. That is, the brown farmer needs to be paid some information rent. However, monetary transfer to the brown farmer must be such that it does not induce the green farmer to sacrifice reputational gain for money, which can be ensured as long as the brown farmer's reservation utility is not very high compared to the green farmer's reservation utility. ${ }^{19}$

Case II Now we argue how the regulator can ensure better environmental outcomes by offering facilitation services under asymmetric information. The regulator can offer a single contract targeting the green type as green type farmers can produce better environmental outcome.

Lemma 8 Suppose that Assumptions 1-5 hold true and the regulator offers the single contract $\left(t_{F}^{G}, F\right)$ under asymmetric information, where $F$ indicates non-monetary incentives (facilitation of biodiversity protection action coupled with social reward) and $t_{F}^{G}(\geq 0)$ denotes the amount of monetary transfer to be made. Then, the following is true.

(a) In the equilibrium under asymmetric information, each type of farmers chooses his 'symmetric information optimal action in the presence of non-monetary incentives', i.e., $x_{F}^{i * *}=x_{F}^{i *}(i=G, B)$, if, in the presence of non-monetary incentives, the green farmer enjoys reputational advantage over the brown farmer and the reputational advantage of the green farmer in the equilibrium under symmetric information does not exceed a critical level: $0<\Delta R_{F}^{*} \leq \widehat{\Delta R}$, where $\Delta R_{F}^{*}=R\left(\vartheta^{G}, x_{F}^{G *}, \theta_{F}\right)-R\left(\vartheta^{B}, x_{F}^{B *}, \theta_{F}\right)$ and $\widehat{\Delta R}=\left[f^{B}\left(x_{F}^{B *}\right)-C\left(x_{F}^{B *}\right)\right]-\left[f^{B}\left(x_{F}^{G *}\right)-C\left(x_{F}^{G *}\right)\right]$.

(b) If $\Delta R_{F}^{*}>\widehat{\Delta R}$, the green farmer cannot signal his true type by choosing the action $x_{F}^{i *}$ and he may not accept the contract. However, the brown farmer always accepts the contract.

Proof See Appendix B.

Offering a single contract designed only for the green type can successfully attract the green farmer if it ensures better reputation than the brown type. The green farmer wants the observers to be able to differentiate him from the brown type. As discussed in Bénabou and Tirole (2011), relative reputation is one of the key motivational sources for individuals to take pro-social actions (also see Ellingsen and Johannesson 2008; Vesterlund 2003). The

\footnotetext{
${ }^{19}$ If the brown farmer's reservation utility is sufficiently higher than that of the green farmer, the green farmer extracts information rent. If $\underline{U^{B}}>\underline{U^{G}}+\frac{\left(v^{B}-\vartheta^{\mathrm{G}}\right)\left(U^{G}-\Psi_{N}^{B *}\right)}{\vartheta^{\mathrm{G}}}$, the least cost implementation of the symmetric information equilibrium levels of biodiversity protection actions in absence of non-monetary incentives calls for offering (a) the symmetric information equilibrium amount of monetary transfer to the brown farmer $\left(t_{N}^{B * *, s}=t_{N}^{B}\right)$ and (b) more than the symmetric information equilibrium amount of monetary transfer to the green farmer $\left(t_{N}^{G * *, s}>t_{N}^{G}\right)$. In this case, the required monetary compensation is sufficiently large to induce the brown farmer to participate, such that the green farmer has an incentive to pretend to be brown and choose lower biodiversity protection action. Thus, now, the green farmer needs to be paid more than the amount paid under symmetric information. In the intermediate case, $\underline{U^{G}}+\frac{\left(v^{B}-\vartheta^{\mathrm{G}}\right)\left(\underline{U}^{G}-\Psi_{N}^{G *}\right)}{\vartheta^{\mathrm{G}}} \leq \underline{U^{B}} \leq \underline{U^{G}}+\frac{\left(v^{B}-\vartheta^{\mathrm{G}}\right)\left(\underline{U}^{G}-\Psi_{N}^{B *}\right)}{\vartheta^{\mathrm{G}}}$, the symmetric information equilibrium outcomes can be implemented under asymmetric information without altering the monetary transfers. In this case, the differences in terms of reputation and reservation utility of two types of farmers are such that, under asymmetric information, no one has any incentive to mimic the other type.
} 
green type would be happy to take more action to ensure such a 'honour' value. However, if it requires more than his optimal action, he may not participate in the program.

Next, we focus a menu of contract as the regulator wants a brown farmer to participate as well. Suppose that the regulator offers a menu of contracts $\left\{\left(x_{F}^{G}, t_{F}^{G}\right),\left(x_{N}^{B}, t_{N}^{B}\right)\right\}$, such that $\left(x_{F}^{G}, t_{F}^{G}\right)$ is meant for the green farmer, while the contract $\left(x_{N}^{B}, t_{N}^{B}\right)$ is meant for the brown farmer. Given this menu of contracts, each type of farmer will participate in undertaking biodiversity protection action and will also self-select the contract meant for him provided their participation constraints and incentive compatible constraints are satisfied.

Lemma 9 Suppose that Assumptions 1-5 hold true and the regulator offers the menu of contracts $\left\{\left(t_{F}^{G}, F\right),\left(t_{N}^{B}, N\right)\right\}$, where $F$ indicates non-monetary incentives (facilitation of biodiversity protection action coupled with social reward), $N$ indicates no non-monetary incentive, and $t_{F}^{G}(\geq 0)$ and $t_{N}^{B}(\geq 0)$ denote monetary transfers under $F$ and $N$, respectively, to implement the symmetric information level optimal action. Then, under asymmetric information, the regulator can ensure that in the equilibrium the green farmer receives $t_{F}^{G}$ and undertakes biodiversity protection action $x_{F}^{G * *}=x_{F}^{G *}$, while the brown farmer receives $t_{N}^{B}$ and undertakes the action $x_{N}^{B * *}=x_{N}^{B *}$, if $t_{F}^{G}(\geq 0)$ and $t_{N}^{B}(\geq 0)$ satisfy the condition

$$
\frac{\operatorname{Max}\left\{\Psi_{F}^{B *}, \Psi_{F}^{B}\left(x_{F}^{G *} \mid E\left(\vartheta \mid x_{F}^{G *}, t_{F}^{G}\right)=\vartheta^{G}\right)\right\}-\Psi_{N}^{B *}}{\vartheta^{B}} \leq t_{N}^{B}-t_{F}^{G}<\frac{\Psi_{F}^{G *}-\Psi_{N}^{B *}}{\vartheta^{G}}
$$

where $x_{F}^{G *}$ and $\Psi_{F}^{G *}$ are, respectively, green farmer's symmetric information equilibrium actions and gross utility (total utility minus the utility from monetary transfer, if any) when he receives non-monetary incentives; $x_{N}^{B *}$ and $\Psi_{N}^{B *}$ are, respectively, brown farmers symmetric information equilibrium actions and gross utility when he does not receive any nonmonetary incentive; $\Psi_{F}^{B *}$ is the equilibrium gross utility of the brown farmer under symmetric information when he receives non-monetary incentives; $\Psi_{F}^{B}\left(x_{F}^{G *} \mid E\left(v \mid x_{F}^{G *}, t_{F}^{G}\right)=v^{G}\right)$ is the gross utility of the brown farmer when he is successful in pretending that he is actually green by choosing the contract $\left(t_{F}^{G}, F\right)$ and action $x_{F}^{G *} \cdot{ }^{20}$

Proof See Appendix B.

Lemma 10 Suppose that Assumptions 1-5 hold true. Then even under asymmetric information the regulator can ensure that only the green farmer receives facilitation services and social rewards and the corresponding symmetric information equilibrium level of biodiversity protection action is chosen by him, while the brown farmer also participates in biodiversity protection activity by choosing his symmetric information equilibrium level of biodiversity protection action in absence of any non-monetary incentive, at the least cost by receiving $t_{F}^{G * *, O}$ by the green farmer and $t_{N}^{B * *, O}$ by the brown farmer, where $t_{F}^{G * *, O}=0$ and $t_{N}^{B * *, O}=\frac{\operatorname{Max}\left\{\Psi_{F}^{B *}, \Psi_{F}^{B}\left(x_{F}^{G *} \mid E\left(\vartheta \mid x_{F}^{G *}, t_{F}^{G}\right)=\vartheta^{G}\right)\right\}-\Psi_{N}^{B *}}{\vartheta^{B}}>t_{N}^{B *}$.

Proof See Appendix B.

${ }^{20}$ Suppose that Assumption 5 does not hold true, instead the following holds $\Psi_{\mathrm{N}}^{\mathrm{B}^{*}}<\Psi_{\mathrm{F}}^{\mathrm{B}^{*}}<\underline{\mathrm{U}^{\mathrm{B}}}$ and $\Psi_{\mathrm{N}}^{\mathrm{G}^{*}}<\underline{\mathrm{U}^{\mathrm{B}}}<\Psi_{\mathrm{F}}^{\mathrm{G}^{*}}$. Under asymmetric information, the regulator can implement the desired environmental outcome albeit the cost involved may be higher. See Appendix B for details. 
Lemmas 9 and 10 construct a menu of contracts for G-type and B-type farmers such that the contracts can separate the types out. The G-type farmer will not have any incentive to choose the contract for the B-type farmer and vice versa. The G-type farmer does not have any incentive to mimic a brown farmer. The regulator must ensure that the contract for the G-type farmer satisfies the following participation constraint, i.e., he will participate if his utility from taking optimal action with facilitation and non-monetary incentive is no less than his reservation utility.

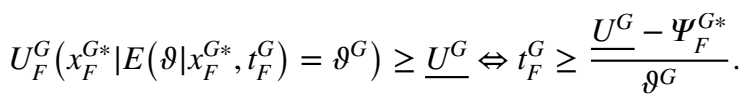

In contrast, the B-type farmer has the incentive to mimic the G-type to gain a good reputation. The contract for the B-type farmer should satisfy his incentive compatible constraint-he will not have any incentive to deviate from his contract and reveal his true type. The contract will be incentive compatible for the brown type if his utility from taking optimal action without facilitation and corresponding monetary incentives (right hand side of the following constraint) should be no less than his utility from choosing the contract meant for the green type.

$$
\operatorname{Max}\left\{\Psi_{F}^{B *}, \Psi_{F}^{B}\left(x_{F}^{G *} \mid E\left(\vartheta \mid x_{F}^{G *}, t_{F}^{G}\right)=\vartheta^{G}\right)\right\}+\vartheta^{B} t_{F}^{G} \leq \Psi_{N}^{B *}+\vartheta^{B} t_{N}^{B}
$$

Solving the utility maximisation problem for each type subject to their participation and incentive compatible constraints will give the optimal outcome stated in Lemma 9 and 10. Note that, given the assumptions $1-5$ hold true, if a regulator offers a menu of contracts similar to the symmetric information contract, she cannot separate the types out as the brown farmer will mimic the green farmer and the green farmer may not participate (see Claim 5 in Appendix B for details).

Moreover, in Lemmas 9 and 10, we have the assumption that $x$ is non-verifiable. If we relax that assumption (i.e., it is not very costly to verify $x$ ), we will have the following. In Lemma 9, the inequality (9) will become: $\frac{\Psi_{F}^{B}\left(x_{F}^{G *} \mid E\left(\vartheta \mid x_{F}^{G *}, t_{F}^{G}\right)=\vartheta^{G}\right)-\Psi_{N}^{B *}}{v^{B}} \leq t_{N}^{B}-t_{F}^{G}<\frac{\Psi_{F}^{G *}-\Psi_{N}^{B *}}{\vartheta^{G}}$, and in Lemma 10, $t_{N}^{B * *, O V}=\frac{\Psi_{F}^{B}\left(x_{F}^{G *} \mid E\left(\vartheta \mid x_{F}^{G *}, t_{F}^{G}\right)=\vartheta^{G}\right)-\Psi_{N}^{B *}}{\vartheta^{B}}>t_{N}^{B *}$. Therefore, when $x$ is verifiable, $t_{N}^{B * *, O V}<t_{N}^{B * *, O}$, if $\Psi_{F}^{B *}>\Psi_{F}^{B}\left(x_{F}^{G *} \mid E\left(\vartheta \mid x_{F}^{G *}, t_{F}^{G}\right)=\vartheta^{G}\right)$. It means, due to non-verifiability of farmers' actions, the regulator will have to incur higher costs in order induce the brown farmer to participate.

Comparing the money-only contract (Case I) and facilitation-social-reward contract (Case II), we conclude in the following lemma that a regulator can save some public fund without compromising with the level of biodiversity protection by exploiting a farmer's social preferences for gaining a green reputation.

Lemma 11 Suppose that Assumptions $1-4$ hold true. Also suppose that $\frac{U^{B}-\Psi_{N}^{G *}}{\vartheta^{\mathrm{B}}}<\frac{U^{G}-\Psi_{N}^{G *}}{\vartheta^{\mathrm{G}}}$. Then, a sufficient condition for $t_{N}^{B * *, O}<t_{N}^{B * *, s}$ to hold true is $R\left(v^{G}, x, \theta_{N}\right)-R\left(v^{B}, x, \theta_{N}\right)>R\left(v^{B}, x, \theta_{F}\right)-R\left(v^{B}, x, \theta_{N}\right) \quad$ whenever $f^{B}(x)=g(x)$. Otherwise, if $f^{B}(x)>g(x), t_{N}^{B * *, O}<t_{N}^{B * *, s}$ holds true whenever relative reputation of a green farmer, $R\left(v^{G}, x, \theta_{N}\right)-R\left(v^{B}, x, \theta_{N}\right)$, is greater than a critical level. Further, $t_{N}^{G * *, s}+t_{N}^{B * *, s}>t_{N}^{G * *, O}+t_{N}^{B * *, O}$ holds true for weaker condition.

Lemma 11 states that the brown farmer will receive less monetary payment under the contract with facilitation and social reward if his reputational gain due to the social reward 
is less than the green farmer's relative reputational value under money-only-contract. This ensures that the contract with facilitation is cost-effective. A green farmer cares about his relative reputational value-his esteem. In the facilitation-social-reward contract, if a brown farmer receives social reward, the green farmer may face an incentive loss-he might anticipate that he would not be able to signal his type. The contract should ensure that the relative reputation of the brown farmer from social reward compared to no-reward should be less than the esteem value of the green farmer, i.e., his relative reputation in the money-only-contract. To ensure the esteem value of the green type, it requires less monetary transfer to attract a green type. That in turn ensures that the brown type needs to be paid less to induce him to choose his own contract.

Proposition Suppose that Assumptions 1-4 hold true. Then under asymmetric information the regulator can ensure better environmental outcomes at less cost by offering a menu of contracts involving both monetary transfers and non-monetary incentives such as facilitation services and social reward compared to offering only monetary incentives.

To sum up, in the presence of asymmetric information, a regulator can implement the symmetric information optimal level of biodiversity protection action in both cases-a menu of monetary contracts without and with facilitation service and social reward. In the first case, both types take the optimal level of actions (i.e., same as in the complete information case without facilitation) and a brown-farmer extracts information rent. In the latter case, a green-farmer takes the optimal level of action (i.e., complete information level with facilitation) and receives social reward only (i.e., no monetary payments) whereas the brown-farmer extracts information rents and takes the optimal action under complete information without facilitation. In the latter case, more public good is created in the equilibrium at less costs as the regulator pays out less monetary compensation compared to the money-only-contract.

\section{Concluding Remarks}

We examined how social preferences affect the workings of voluntary green payment schemes. We analysed the design of an incentive scheme that considers two types of farmers ('green' or brown') under asymmetric information about their true motivation. In the presence of asymmetric information about the true type of the farmer, our mechanism suggests that a regulator can implement the first best level of biodiversity protection action (i.e., symmetric information levels) using monetary contracts without and with facilitation service and social reward. In the former case, a green-farmer takes optimal level of monetary compensation and a brown-farmer extracts information rent. In the latter case, a green-farmer accepts no monetary payments from the regulator whereas the brown-farmer takes optimal level of monetary payments. It implies that a regulator can implement the first best level of biodiversity protection action at less cost with facilitation service and social reward.

The design hinges on the existence of a well-accepted social norm among farmers that environmental management is 'the right thing to do' and that (some) farmers receive esteem from such activities. Results from our incentivised survey and discrete choice experiment support these assumptions. For farmers in Scotland we find that (1) there is a social norm that endangered species protection on private land is the right thing to do; 
(2) taking swift action to protect a species found on private land is more appropriate than doing nothing and waiting for compensation upfront; and (3) farmers care about their reputation of being environmentally responsible such that they are prepared to give up economic benefit for more publicity of their responsible actions. One potential limitation is that the empirical test relies on stated intentions rather than observed behaviour regarding reputation and the local social norm effects.

The design presented requires a good understanding of farmers' willingness and ability to take up environmental activities and of the factors that influence farmers' behavioural change. Our claim about the cost-effectiveness of the proposed mechanism depends crucially on the relationship between the norms and the mix of incentives. It is important to understand whether the proposed policy instruments and existing social norm are conflicting or complementing and how this trade-off evolves over time (e.g., see Acemoglu and Jackson 2017; Nyborg et al. 2016). Experimenting is an effective tool to discover how different mechanisms may affect contribution levels and ambition levels and how this varies across different social/cultural contexts. Our theory relies on the assumption that agents' preferences are stable. It will be useful to empirically test whether farmers' preferences exhibit dynamic inconsistencies in the context of environmental public good creation.

To conclude: we show that a social norm for biodiversity conservation on farmland exists among farmers and that most farmers have preferences for following these social rules. Communication of these rules and adoption rates through meetings and reports in agricultural magazines could make agri-environmental schemes more effective. This will not only reduce scheme expenditure: the norm effect, and the accumulation of the farmer's experience in the scheme management, will increase the ecological results.

The debate about the post-2020 reform of the EUs agricultural policy may offer opportunities to further consider these factors as the European Commission proposes a budgetary shift to more voluntary approaches to incentivise sustainable practices (European Commission 2018). Since 1992, the CAP has seen multiple reforms. The most recent reform was in 2013 for the period of 2014-2020. Farmers and landowners receive payments on a per area basis (Pillar I). To be eligible to receive these Basic Payment Scheme funds, farmers are expected to abide by baseline requirements (Cross Compliance rules), which are based around public, animal and plant health, environment, climate change, good agricultural condition of land and animal welfare. In addition, they need to adhere to greening rules. $^{21}$ To go beyond Pillar I legal requirements, farmers can voluntarily opt for further payments under the Rural Development Pillar II. This is labelled as agri-environmental schemes (AES). In the most recent CAP reform, conservation interests called for a shift of resources toward more targeted conservation initiatives, particularly through Pillar 2 . In the event, the outcome of the reform process retained the balance between the two pillars, but the delivery model offers EU member states higher flexibility with the implementation. ${ }^{22}$

A pattern has emerged across the EU and the UK of agri-environmental schemes being introduced, subjected to some amendments and revisions, then withdrawn and replaced by a redesigned scheme. Each country designs its own schemes. The increased national implementation flexibility and the large budgets involved have resulted in a growing need

\footnotetext{
21 For an evaluation of these rules see Hodge et al. (2015).

${ }^{22}$ For the U.K., the EU funding under CAP Pillar 2 (for rural development and environmental projects) will continue until the current EU funding is used up or 2023, whichever is earliest. The UK will leave CAP Pillar 1 in 2020. This will be replaced by a new system based on public money for public goods. This will allow the funding for Direct Payments for 2020 to continue at the same level as 2019.
} 
for information on specific designs in achieving the higher-level objectives. Linkage needs to be made between top-down legislation at national and European levels and bottom-up research on preferences and trade-offs at more local levels including regional variation in farmers' non-monetary motives. The research toolbox needs to evolve to reflect these changes in agri-environmental policy instruments, objectives and in local stakeholders' increased levels of environmental awareness and changing priorities.

Acknowledgements We thank the referee and two anonymous reviewers for the constructive comments. We thank attendees of the following conferences for their useful comments: EAERE2019; WCERE2018; RES2015, BIOECON2015. This research is partially supported by the European Commission's FP7 project BIOMOT (MOTivations for Ecosystem Services and Alternative Ways to Express the Value of BIOdiversity). Banerjee thanks Indira Gandhi Institute of Development Research for their support while working on the paper with Pal during his visit to the institute.

Open Access This article is licensed under a Creative Commons Attribution 4.0 International License, which permits use, sharing, adaptation, distribution and reproduction in any medium or format, as long as you give appropriate credit to the original author(s) and the source, provide a link to the Creative Commons licence, and indicate if changes were made. The images or other third party material in this article are included in the article's Creative Commons licence, unless indicated otherwise in a credit line to the material. If material is not included in the article's Creative Commons licence and your intended use is not permitted by statutory regulation or exceeds the permitted use, you will need to obtain permission directly from the copyright holder. To view a copy of this licence, visit http://creativecommons.org/licenses/by/4.0/.

\section{References}

Acemoglu D, Jackson MO (2017) Social norms and the enforcement of laws. J Eur Econ Assoc 15(2):245-295

Andreoni J, Bernheim BD (2009) Social image and the 50-50 norm: a theoretical and experimental analysis of audience effects. Econometrica 77(5):1607-1636

Anthon S, Garcia S, Stenger A (2010) Incentive contracts for Natura 2000 implementation in forest areas. Environ Resource Econ 46(3):281-302

Arce DG (2013) Principals' preferences for agents with social preferences. J Econ Behav Organ 90:154-163

Arguedas C, van Soest DP (2011) Optimal conservation programs, asymmetric information and the role of fixed costs. Environ Resource Econ 50(2):305-323

Ariely D, Bracha A, Meier S (2009) Doing good or doing well? Image motivation and monetary incentives in behaving prosocially. Am Econ Rev 99(1):544-555

Ashraf N, Bandiera O, Jack BK (2014) No margin, no mission? A field experiment on incentives for public service delivery. J Public Econ 120:1-17

Banerjee P, Shogren JF (2012) Material interests, moral reputation, and crowding out species protection on private land. J Environ Econ Manag 63(1):137-149

Banerjee S, Cason TN, de Vries FP, Hanley N (2017) Transaction costs, communication and spatial coordination in Payment for Ecosystem Services Schemes. J Environ Econ Manag 83:68-89

Batáry P, Dicks LV, Kleijn D, Sutherland WJ (2015) The role of agri-environmental schemes in conservation and environmental management. Conserv Biol 29(4):1006-1016

Bénabou R, Tirole J (2006) Incentives and prosocial behaviour. Am Econ Rev 96(5):1652-1678

Bénabou R, Tirole J (2011) Laws and norms (No. w17579). National Bureau of Economic Research

Besley T, Ghatak M (2008) Status incentives. Am Econ Rev 98(2):206-211

Bowles S (2008) Policies designed for self-interested citizens may undermine "the moral sentiments": evidence from economic experiments. Science 320(5883):1605-1609

Bowles S, Hwang SH (2008) Social preferences and public economics: mechanism design when social preferences depend on incentives. J Public Econ 92(8-9):1811-1820

Brennan G, Pettit P (2004) The economy of esteem. Oxford University Press, Oxford

Carpenter J, Seki E (2011) Do social preferences increase productivity? Field experimental evidence from fishermen in Toyama Bay. Econ Inq 49(2):612-630 
Dessart FJ, Barreiro-Hurlé J, van Bavel R (2019) Behavioural factors affecting the adoption of sustainable farming practices: a policy-oriented review. Eur Rev Agric Econ 46(3):417-471

Ellingsen T, Johannesson M (2008) Pride and prejudice: the human side of incentive theory. Am Econ Rev 98(3):990-1008

European Commission (2018) Proposal for a regulation of the European Parliament and of the Council establishing rules on support for strategic plans to be drawn up by Member States under the Common agricultural policy (CAP Strategic Plans). European Commission, Brussels. https://eur-lex.europa.eu/ resource.html?uri=cellar:aa85fa9a-65a0-11e8-ab9c-01aa75ed71a1.0003.02/DOC_1\&format=PDF

Fehr E, Leibbrandt A (2011) A field study on cooperativeness and impatience in the tragedy of the commons. J Public Econ 95(9-10):1144-1155

Fehr E, Schmidt KM (1999) A theory of fairness, competition, and cooperation. Q J Econ 114(3):817-868

Frey BS (2006) Giving and receiving awards. Perspect Psychol Sci 1(4):377-388

Hodge I, Hauck J, Bonn A (2015) The alignment of agricultural and nature conservation policies in the European Union. Conserv Biol 29:996-1005

Kimbrough EO, Vostroknutov A (2016) Norms make preferences social. J Eur Econ Assoc 14(3):608-638

Kosfeld M, Neckermann S (2011) Getting more work done for nothing? Symbolic awards and worker performance. Am Econ J Microecon 3(3):86-99

Krupka EL, Weber RA (2013) Identifying social norms using coordinating games. Why does dictator games sharing vary? J Eur Econ Assoc 11(3):495-524

Kuhfuss L, Preget R, Thoyer S, Hanley N, Le Coent P, Desole M (2016) Nudges, social norms and permanence in agri-environmental schemes. Land Econ 92:641-655

Lacetera N, Macis M (2010) Social image concerns and prosocial behavior: field evidence from a nonlinear incentive scheme. J Econ Behav Organ 76(2):225-237

Latacz-Lohmann U, Breustedt G (2019) Using choice experiments to improve the design of agri-environmental schemes. Eur Rev Agric Econ 46(3):495-528

Lokhorst AM, Staats H, van Dijk J, van Dijk E, de Snoo G (2011) What's in it for me? Motivational differences between farmers' subsidised and non-subsidised conservation practices. Appl Psychol 60(3):337-353

Lourenço JS, Ciriolo E, Rafael Ameida S, Dessart FJ (2016) Behavioural insights applied to policy: country overview 2016. European Commission, Brussels. http://publications.jrc.ec.europa.eu/repository/handl e/JRC100547

Mills J, Gaskell P, Ingram J, Chaplin S (2018) Understanding farmers' motivations for providing unsubsidised environmental benefits. Land Use Policy 76:697-707

Nyborg K, Anderies JM, Dannenberg A, Lindahl T, Schill C, Schlüter M, Adger WN, Arrow KJ, Barrett S, Carpenter S, Chapin FS (2016) Social norms as solutions. Science 354(6308):42-43

OECD (Organisation for Economic Co-operation and Development) (2015) Public goods and externalities: agri-environmental policies in selected countries. OECD, Paris

OECD (2017) Behavioural insights and public policy. Lessons from around the world. OECD Publishing, Paris. https://doi.org/10.1787/9789264270480-en

Reuben E, Riedl A (2013) Enforcement of contribution norms in public good games with heterogeneous populations. Games Econ Behav 77(1):122-137

Riley M (2016) How does longer term participation in agri-environment schemes [re]shape farmers' environmental dispositions and identities? Land Use Policy 52:62-75

Rutto E, Garrod G (2009) Investigating farmers' preferences for the design of agri-environment schemes: a choice experiment approach. J Environ Plan Manag 52(5):631-647

Vaissière AC, Tardieu L, Quétier F, Roussel S (2018) Preferences for biodiversity offset contracts on arable land: a choice experiment study with farmers. Eur Rev Agric Econ 45(4):553-582

Vesterlund L (2003) Informational value of sequential fundraising. J Public Econ 87:627-657

Wossink GAA, van Wenum JH (2003) Biodiversity conservation by farmers: analysis of actual and contingent participation. Eur Rev Agric Econ 30(4):461-485

Publisher's Note Springer Nature remains neutral with regard to jurisdictional claims in published maps and institutional affiliations. 